\title{
Challenges Experienced by Students Studying through Open and Distance Learning at a Higher Education Institution in Namibia: Implications for Strategic Planning
}

\author{
Amalia Ilonga ${ }^{1}$, Daniel Opotamutale Ashipala ${ }^{1} \&$ Nestor Tomas ${ }^{1}$ \\ ${ }^{1}$ Department of General Nursing Science, School of Nursing, Faculty of Health Sciences, University of Namibia \\ (UNAM), Rundu, Namibia \\ Correspondence: Mr Daniel Opotamutale Ashipala (Senior Lecturer), Department of General Nursing Science, \\ School of Nursing, Faculty of Health Sciences, University of Namibia (UNAM), PO Box 88, Kaisosi Road, Rundu, \\ Namibia. E-mail: dashipala@unam.na, ORCiD ID: https://orcid.org/0000-0002-8913-056x
}

Received: March 8, 2020

Accepted: May 16, 2020

Online Published: May 19, 2020

doi:10.5430/ijhe.v9n4p116

URL: https://doi.org/10.5430/ijhe.v9n4p116

\begin{abstract}
Online learning remains one of the most powerful enablers and accelerators for realising higher education studies by enhancing teaching by means of innovative technologies and pedagogies. However, the success rate of students studying through Open and Distance Learning (ODL) remains very low. Therefore, institutions of higher learning in Namibia should continuously establish and assess the challenges affecting the students who opt to study via distance mode to devise strategies required to address such challenges. The objective of this study was to understand the challenges experienced by students studying through ODL at Higher Education Institution (HEI) in Namibia and establish the challenges they face. A qualitative, phenomenological, explorative, descriptive and contextual research strategy was employed in this study to explore and describe challenges experienced by students' studying through ODL at HEI' satellite campus in Namibia. A purposive sampling was utilised in the selection of participants. Data were collected from participants using semi-structured interviews with nine participants. Three themes were identified, namely, the reasons why students chose to study through ODL programme, challenges experienced by students studying through ODL and mechanisms for improvement. The findings of this study call for well-articulated plans and actions to address the challenges faced by students studying in the distance e-learning mode. The study recommended that both Lecturers and ODL programme Administrators should undergo refresher training on distance education annually to ensure that they are aware and can address the challenges faced by their students.
\end{abstract}

Keywords: open and distance learning, online learning, challenges, experiences, student, satellite campus, higher education institution

\section{Introduction}

Online learning remains one of the most powerful enablers and accelerators for realising higher education studies, enhancing teaching by means of innovative technologies and pedagogies (Fernando, 2018). The development of education in Namibia is guided by four broad goals, namely, access, equity, quality and democracy (Government of the republic of Namibia, 2002). Studying through ODL remains one of the most convenient modes of study, promoting access to higher education in Namibia. This mode focuses on opening access to education and training provision, freeing students from the constraints of time and place and affording them an opportunity to access a form of education that is flexible for individual students. With the emergence of the fourth industrial revolution characterised by the digitalisation of fusion technology, open and distance learning has the potential to provide future generations with the appropriate skills and knowledge through technological advancement (Valdes, Comendador, Sanz \& Catan, 2018).

To address the needs of the fourth industrial revolution in education, higher learning institutions should continue to integrate innovative methods to enhance the teaching and learning process (Halili, 2019). In order to do so, universities should be able to track the demands for skills in industry and move rapidly to ensure that students complete their education ready to add real value to the business world. The 21 st century requires technological learning that includes digital literacy's, collaboration, complex communication and systems thinking skills, among others. Initially, in order to be in line with online learning, Higher Education Institution (HEI) are expected to offer 
courses and platforms that sustain the use of multidimensional abilities, skills and the use of media and technology as a supportive system in higher education (Mahlangu, 2018).

Individuals seeking to further their education at university level have the option to either register through the "traditional" face-to-face delivery, online or mixed modes of study (Gillett-Swan, 2017). The proliferation of online learning programmes is changing the way educators see and approach learning and teaching worldwide because of the increased online education opportunities (Palvia et al., 2018). Layton (2017) states that online learning is educational tools that is based and is accessible on the internet anytime. This would allow an individual to learn from place and time of his or her comfort. E-learning is therefore an opportunity to learn without being restricted by geographical or time constraints and it has been reported as improving the quality of learning, increasing engagement and enhancing students' motivation (Arasaratnam \& Northcote, 2017).

Despite the fact that integrating distance and e-learning clearly has advantages in the education system, some HEIs have been experiencing challenges in its implementation Darling-Hammond, Flook, Cook-Harvey, Barron \& Osher, (2019). HEIs worldwide are facing a variety of challenges related to the successful implementation, maintenance and growth of online programmes Mahlangu, (2018). Challenges in the online education arena are being experienced worldwide from Africa to the Americas, Europe and Asia Palvia, Aeron, Gupta, Mahapatra, Parida, Rosner \& Sindhi, (2018). In the United States of America (USA), challenges that may result in the failure of distance and online education are institutional factors such as a lack of understanding of online pedagogy, online learning styles, lack of administrative support for online education, the number of students enrolled, faculty qualifications, tuition rates and the length of the programme (Kentnor, 2015).

Challenges affecting online learning in the Middle East include low internet penetration, low public esteem for online learning, and a lack of online educational repositories in the Arabic language (Palvia et al., 2018). To deal with these challenges and promote e-learning in Saudi Arabia, collaborations with institutions of higher learning, improving quality standards, and developing rules and regulations for governing e-learning were initiated (Palvia et al., 2018). In Africa, ICT capacity overall has not evolved significantly, although online learning seems to be heading toward a critical mass and may have a major impact (Palvia et al., 2018). In South Africa there were gaps in policy understanding by intermediaries like district and provincial officials, resulting in several problems relating to the actual implementation of a national online learning policy (Vandeyar, 2015). Distance and online learning raises significant challenges in the technological research arena. Although distance and online learning training has been ongoing at a HEI's satellite campus for 28 years now, no data exist regarding students' experiences with ODL programme. Therefore, the aim of this study was to explore and describe students' challenges associated with the online and distance learning mode at a selected satellite campus of HEI in Namibia.

Teaching course materials and classrooms have become sophisticated and complex in the ways in which they have been converted into new forms. Allen, Seaman, Poulin, and Straut (2015) reported that more than two-thirds of academic leaders believe that online learning was a "critical" component to the long-term practicability of institutions. As this has become a demand at many institutions, there has been steady growth in online learning programmes across HEIs. The specific HEI satellite campus offers a wide range of undergraduate and postgraduate programmes; however, despite its efforts to cater for students who are unable to attend the full-time programme by introducing a distance and online learning programme in its curriculum, a high percentage of the students who register through this learning mode discontinue their studies and others have taken several extra years to complete (Du Plessis, Alexander, Ashipala \& Kamenye, 2016). Empirical evidence revealing the students' challenges experienced at the selected satellite campus has yet to be undertaken.

Accordingly, the following research questions were posed:

1. What challenges are experienced by students' in pursuing their studies through ODL at satellite campus of HEI in Namibia?

2. What are the factors contributing to the challenges affecting students studying through ODL at a satellite campus of HEI in Namibia?

\section{Research Design and Methods}

This study used a qualitative, phenomenological, explorative, descriptive and contextual research strategy (Burns \& Grove, 2015; Ellis, 2018; Green \& Thorogood, 2018; Holloway \& Galvin, 2016) to gain an in-depth understanding of the challenges experienced by students studying through ODL programme at a selected satellite campus of HEI in Namibia. A qualitative approach was considered appropriate for this study because it helps a researcher to understand the thoughts and feelings of research participants. Another advantage of this approach was that it 
generates data that intensifies insight into the phenomenon itself rather than merely providing representative information (Polit \& Beck, 2017). The purpose of an exploratory research was to gather preliminary information that helped define problems and suggest further studies. Furthermore, the design used also explored the way participants made sense of their surroundings, experiences and understandings of a phenomenon (Maree, 2016).

\subsection{Context of the Study}

The satellite campus in which this study was conducted belongs to one of the largest HEI in the country with the diverse student population from 43 countries. Although a relatively young Institution of 28 years, it has grown to support a student population of 24,759 with 12 campuses and seven regional centres countrywide. The training institution offers full-time, part-time and distance courses. The vision of HEI is to be a beacon of excellence and innovation in teaching, research and extension services. As supported by HEI Act 18 of 1992, the aim of the HEI is to provide higher education, to undertake research and to advance and disseminate knowledge. It also provides extension services and encourages the growth and nurturing of cultural expression within the context of Namibian society. Moreover, its aim is to further training and continuing education and to contribute to the socioeconomic aspects related to the Namibian people. Additionally, the HEI seeks to direct the economic development of Namibia and to foster relationships with any person or institution, both nationally and internationally. Therefore, online learning can be used in intersecting the HEI vision and mission by enhancing teaching using new innovative technologies and pedagogies.

The ODL at this particular HEI was established with the vision to strive to become the leading ODL centre in the country and beyond by enabling people to achieve their full potential through accessible, innovative and flexible learning, blended with eLearning, using the flipped classroom and other innovative concepts and approaches. The mission is to provide accessible quality higher education and to create opportunities for professional development for adult members of the community by offering open and flexible learning through distance and continuing education programmes. ODL caters for people who, for a variety of reasons, cannot attend any full time university programmes for further studies.

\subsection{Participants and Sampling}

Sampling is the process for selecting a portion of the population to represent the whole population (Harvey \& Land, 2016). It is a subset chosen from the sampling frame that represents the entire population (Taherdoost, 2016). Purposive sampling was used to select the participants for this study from the population, namely, students studying via the distance mode at a selected satellite campus of HEI. Polit and Beck (2017) describe purposive sampling as a non-probability sample that is selected based on the characteristics of a population and the objectives of the study. Participants were selected for the study until data saturation occurred. The selected satellite campus of HEI has three faculties namely: Health Science, Education and Management Sciences.

\subsection{Data Collection Procedures}

Data were collected by means of semi-structured interviews using an interview guide. The face-to-face interview allowed the researcher to observe any non-verbal communication and allowed both the interviewer and the participant to seek any clarification necessary. Research questions that were used in the interview included: 1 . the reasons why students chose to study through the distance mode, and 2. the challenges experienced by students studying through ODL programme. These questions assisted the researchers to probe view point of the students who were studying through ODL. Participants were included in the interviews based on their willingness to participate in the study and a voice recorder was used with the participants' permission to record all interview sessions.

\subsection{Data Analysis}

The audio recordings of the interviews were fully transcribed and a content analysis was used to analyse the data since this is the most reliable strategy used in qualitative research, giving the researcher a chance to organise the information into themes and subthemes (Polit \& Beck, 2017). Each interview was analysed for units of meaning, and then clustered together to form themes and subthemes. Each theme was discussed with relevant quotations from the participants and relevant literature was used to control the findings.

\subsection{Quality Measures}

The trustworthiness of the study was ensured by using the criteria of Lincoln and Guba (1965), namely, by assuring the credibility, transferability, dependability and confirmability of the study (Polit \& Beck, 2017). Trustworthiness is important in qualitative research in order to support the argument that the findings of the inquiry are worthy and accurate. Credibility was achieved through prolonged engagement with the participants in the field until data 
saturation was reached; thus, an in-depth understanding of the proposed phenomenon was gained. Interviews were recorded and subsequently the interview transcriptions were compared with the recordings to confirm that they were those of the participant. Transferability was ensured by the researcher, as thick descriptions of the collection and provision of data within the context were given, which also depended on data saturation. Supporting verbatim quotations were provided in the data analysis as part of the description of the findings. In order to ensure dependability, the data in this study were recorded and the transcripts are obtainable upon request. Data findings for this study were controlled with related literature. The research design followed was also clearly and fully described in the study. Confirmability of data was enhanced thorough documentation and the transparency of the methodology, data analysis and conclusions.

\subsection{Ethical Considerations}

The research proposal was submitted to the Ethics and Research Committee at HEI for ethical approval, which was subsequently granted. The researcher obtained the participants' personal consent to their participation in the study, after the purpose and significance of the study had been explained to them. Confidentiality of information was assured and the privacy of all participants was respected. This was achieved by keeping all the research instruments (including the recorded audio) and findings in a laptop with an encrypted password to which only the researcher and the research supervisor had access. Although anonymity cannot be completely guaranteed in qualitative research because it involves direct contact with the participant, in this study the researcher took care to ensure that the names of the participants were not be disclosed and would not be linked to the data. Furthermore, participant's right to self-determination was respected by allowing them to decide for themselves whether or not to participate in the study with no risk of penalty. Participants were given the right to withdraw at any time or to withhold any information they did not want to disclose.

\section{Findings}

\subsection{Description of Participants}

A total of nine participants were interviewed for this study with an age range of between 22 and 35 years. Of these, $44.5 \%$ were male and $55.5 \%$ were female and $77.8 \%$ of participants were single while $22.2 \%$ were married. Employment status revealed that $77.8 \%$ of participants had full-time jobs, with $22.3 \%$ being unemployed. In addition, $77.8 \%$ of the participants were registered for the Faculty of Education, $11.1 \%$ were registered with the Faculty of Health Sciences (Nursing), and $11.1 \%$ were registered with the Faculty of Economics. Further, $77.8 \%$ of all participants were in their second year while $22.2 \%$ were in their fourth year.

\subsection{Presentation of Findings}

The following three themes and categories were identified as the experiences of the students studying through ODL at the selected satellite campus of HEI.

Table 1. Themes and categories

\begin{tabular}{cl}
\hline \multicolumn{1}{c}{ Themes } & Categories \\
\hline 1. The reasons why students chose to study through the & - Only opportunity \\
& - Balance between work and school \\
& - For skill improvement \\
\hline 2. The challenges experienced by students studying through & - IT-related challenges \\
ODL programme & - Lecturer time-related challenges \\
& - Institution-related challenges \\
\hline 3. Mechanism for improvement & - Procurement of resources \\
& - Expansion of centres \\
\hline
\end{tabular}

The detailed description of themes and categories in this study are discussed below:

\subsection{Theme 1: The Reason Why Students Chose to Study through the Distance Mode}

This theme explains the reasons why students chose to study through ODL programme at the satellite campus of HEI in Namibia. Students had different answers and reasons to why they opted to study through the distance learning mode and not full time 


\subsubsection{Only Opportunity}

Most students revealed that studying through the distance mode was the only opportunity they had to be in school.

It's the only opportunity I have ... [P2]

For me I think it was the only opportunity I had in order to keep my job and further my studies at the same time. [P9]

...I am employed and this is the only option I had to further my studies. [P7]

...I was studying on full time and as I uncounted challenges already due to financial, I decided I need a job to at list pay for my own school fees. [P6]

...Much cheaper compared to full time studies cause of financial issues... [P4]

3.3.2 Balance between Work and School

As some of the participants were employed, they stated that distance learning allowed them to balance their work and studies so that they did not have to leave work to go and study.

Because I'm working, I cannot resign to allow me to go study full time, thus why I'm doing distance. [P3]

... Because it fits my learning around my work and my whole life ... [P5]

... Keep my job and further my studies at the same time. [P9]

...It allows me to balance my school with my work. [5]

It allows me to work and also concentrate on my school at the same time. [P4]

\subsubsection{For Skill Improvement}

Participants saw ODL as a way of improving their skills and knowledge, which they could immediately apply to their job. A quotation from one of the participants highlighted that

... ODL is the only place where by I can add value to my skills and broaden my knowledge... [P1]

It allows me to incorporate what I learn at school practically at my work place... [P7]

It helps me a lot as the course I am doing is related to my field of work. I am able to combine the two together. [P8]

The advantages of studying through ODL prompted most participants to describe their learning experience as a good experience.

...Its flexible because I can do my assignment at any time. [P]

I usually set my own pace of studying. [P5]

I am able to schedule my own study period to the way it suits me. [P8]

\subsection{Theme 2: The Challenges Experienced by Students Studying through the Distance Mode}

This theme reflects the challenges experienced by students studying through ODL programme. Students expressed these challenges as IT-related challenges, lecturer time-related, and institution-related challenges.

\subsubsection{IT-related Challenges}

This category refers to issues related to disorganisation in the ODL programme. Students stated that although they registered online, certain modules did not appear on their portals. When modules go missing from the portal, the participants revealed that they were required to travel to their centres in order to request the student support officers to add them back onto the portal, which was an inconvenience.

I had a problem when I registered in second semester, some of my modules where missing from the portal. [P1]

I registered myself but some modules were not there. I had to travel to my centre for them to be added; it's also not convenient for me, because I was spending time with my family. [P1]

I had modules missing from my portal after I have registered. [7]

After I had registered I went on my portal and one module was missing. I was then forced to go my centre to fix the problem. [P9]

Even when the modules were on the portal, participants sometimes experienced challenges such as missing marks for assignments they had completed. This resulted in participants being forced to repeat the module if the marks were not uploaded again. 
Challenges that I encounter are marks being missing on the portal. [P9]

This other time I encountered a problem whereby one of my modules had CA marks that are missing. [P8]

Most of the time, marks go missing from our portal. [P7]

In cases where marks were uploaded on the system, they were sometimes wrong and did not accurately reflect the students' scores in the test or assignment. In the end, participants had to go to their centres to have the marks corrected. This is challenging for students who live far from the centres as they then have to take time off work.

Sometimes they enter continuous assessment marks (CAs) that is wrong. [P5]

They uploaded wrong assignment marks on my portal. [P7]

They can sometimes upload wrong test marks on your portal. [9]

Sometimes those people only enter one assignment mark on the portal. [P5]

One of the major challenges according to the participants is the unreliable internet access. Since the programme is reliant on connectivity, students described the internet provided by the university as slow in uploading or even just accessing the portal.

Telecom Namibia (TN) devices are very slow sometimes, especially when you are submitting your assignments, it can be a problem in many cases. It may fail. [P2]

...The TN mobile that we get are very slow. [P4]

...Sometimes I don't have access to tests since I used to work in the field, I will not have access to the internet, I will not do that test and at the end of the year I will not qualify to write the examination. [P6]

It's very difficult to access the internet. [P4]

Internet connectivity affected the participants who reside in the rural areas even more, with one participant verbalising that:

Especially with us that stay in the rural area its worse because the network there is much slower... [P4]

For me, as work out of town, I have difficulties accessing my portal due to poor internet. [P7]

The internet is against us who live in poor internet connected areas. [9]

The TN mobile is very slow. [P8]

Poor internet connectivity posed a big challenge as some students failed to access assignments and uploads them on time. It also became a challenge to write a test online as the internet was slow.

I will not have access to internet; I will not do that test, at the end of the year I will not

Qualify to write an exam. [P6]

You won't see your assignment on time and then you will not have enough time to work on it. [P4]

As a solution to the slow internet, the students had to purchase faster internet devices that would allow them to access their portals more effectively. Most students indicated that this could be costly for them, as they had to spend their own money to purchase internet data.

The internet is costly. [P7]

I have to buy extra data just so I'm able to complete my assignments. [P7]

It's costly to buy extra data. [P9]

\subsubsection{Lecturer Time-Related Challenges}

Most of the participants were of the opinion that the lecturers delayed marking the assignments. Students further elaborated that when assignments are delayed and students fail to obtain $40 \%$ in the assignments, they tend to miss the resubmission date. When students missed the second deadline, the possibility of them not qualifying to write examinations is high and, unless they are given a second chance, they might end up repeating the module. The participants also revealed that not everyone was lucky enough to be given a second chance. This resulted in them having to spend more money and to prolong their studies.

Sometimes the assignments are not marked on time. [P4]

Sometimes you will receive assignments late. [P4] 
There is no second option on distance to re-submit. [P6]

Participants also felt that there was a lack of face time with the lecturers. Lecturers were supposed to meet students twice a year during the recess period but lecturers often fail to show up. As a result, students often travel to HEI to attend lectures. Participants believed that this period should be for them to meet the module lecturers and discuss the challenges that they were facing with the module with them.

Some lecturers refuse to offer us vocational classes at this campus; one had to travel to Windhoek for further assistance. [P1]

It's difficult to communicate with lectures since we do not have lecturers at Rundu campus. [P6]

During recess when you reach there for the vacation school sometimes the lecturer is not available, it's like you wasted your time. [P9]

You will not get tutors... [P6]

The participants also revealed that they felt discriminated against by the way they were handled compared to full-time students and those on the main campus. Participants also felt that the lecturers did not prioritise them and they were being treated unfairly compared to full-time students.

We are not treated fairly. [P1]

Sometimes you call lectures and they will ignore you since they don't know you. [P6]

They don't even consider us. [P6 and 8]

\subsubsection{Institution-Related Challenge}

Students were required to collect study materials from their registered centres once they have completed the registration process. The materials include module books and study guides that students have to use throughout the year to aid their study. In the interviews, the participants stated that when they approach the ODL office to enquire about the study materials they are often told that study materials are finished, as there is only a limited number.

I am suffering with the material; the materials are just not enough at all. [P5]

You will not have enough materials... [P6]

We do not receive enough study materials... [P7]

Sometimes they provide us with materials only mid-year and this is not is not convenient. [P9]

Participants further stated that they are not getting value for money because they pay for modules but end up not getting the necessary material for the modules.

They should obviously provide us with materials because we are giving them money and they are not giving us enough resources. [P8]

We are giving them money but they are not giving us enough resources. [5]

...Our money is not valued. [9]

\subsection{Theme 3: Mechanism for Improvement}

\subsubsection{Procurement of Resources}

All students agreed that the cause of the assignments being late is the shortage of staff; hence, they all recommended that the selected satellite campus of HEI should employ more staff that could deal only with distance students. They felt that the number of students overwhelms the current lecturers, as they have to cater for both full-time and part-time students.

So my suggestion is they should get extra staff, those that are willing just to help us during recess because I also understand the other lecturers they need a break so yah. [P7]

They need to hire more lecturers... [P6]

They need to get extra stuff. [P4]

Students elaborated that the HEI ODL programme in particular should ensure that all students that are registered for the programme receive all the study material for the modules that they have registered for.

They should provide us with enough material ... [P5]

They should make sure that every student that registered for a certain module receives material. [P7] 
They need to take responsibly that all students registered with the centre gets the required materials. [P9]

\subsubsection{Expansion of Centres}

Another recommendation suggested was for the University to ensure that it has centres in all towns where students can go and make enquiries as they live far from their centres.

In every town they need to provide a centre where you can just and submit your assignments or do your enquiries. [P2]

They need to reach all the students throughout the country by ensuring that there are centres in each town. [P7]

We need centres that are close to us who are living in remote areas. [P7]

The must ensure that there are centres near to students at their nearest towns... [P8]

\section{Discussion of Findings}

The purpose of this study was to understand the challenges experienced by students studying through ODL at a selected satellite campus of HEI in Namibia. This section presents the discussion of the findings in accordance with the themes that emerged from the study, namely, the reasons why students chose to study through ODL programme, IT-related challenges, lecturer time-related challenges, institution-related challenges and mechanisms for improvement.

\subsection{The Reason Why Students Chose to Study through the Distance Mode}

The reasons most of the students chose to study through the distance mode because they were employed and unable to quit their jobs to study full-time. Therefore, ODL provided them with an opportunity to pursue their studies at their own pace, while keeping the jobs. These findings were similar with those of Mathew and Iloanya (2016) who found that ODL offers learners the opportunity to learn at anytime from anywhere at their own pace. Distance learning programmes offer students the flexibility to pursue the courses they have enrolled for while fulfilling other work, family or academic commitments (Fincham, 2017). This study also revealed that studying through the distance mode helped participants to add value to their skills and broaden their knowledge. According to Nair (n.d.), students were able to incorporate what they have learnt in the workplace and this helped them improve their skills.

\subsection{The Challenges Experienced by Students Studying through ODL Programme (IT Related Challenges)}

Participants in this study revealed that the operating system posed a number of challenges for the programme. According to the participants, the system was not reliable or convenient as modules and marks constantly go missing. Another challenge observed by the students was that the marks uploaded onto their portals were often incorrect. This may had resulted in students failing the modules and having to re-register the following year. Similarly, Mathew and Iloanya (2015), in a study conducted in Botswana, revealed that distance students faced challenges related to accessing the technology as well as the presence of the digital divide. Secondly, this study found that access to technology, the internet in particular, was a challenge for students, especially for those living in remote and rural areas where there is no electricity. Challenges in accessing network could be a result of poor infrastructure. Kanwar, Carr, Ortlieb, and Mohee (2018) stated in this regard that ODL and technology had become increasingly interconnected; hence, a lack of electricity and internet access could be a barrier to internet adoption. Bearing in mind that the ODL programme relied heavily on technology (internet), many of the study participants expressed that they had encountered challenges with accessing their portals due to poor internet connectivity. Although the selected satellite campus of HEI provides internet SIM cards (TN mobile) which were loaded with internet data every month, the participants emphasised that connectivity was unreliable, leading to problems in uploading their assignments on the portal. Moreover, poor network connectivity meant that students often assessed their assignments late or missed online tests. Hence, students might end up failing and thus repeating the modules. In a similar study by Ndongfack (2016) it was reported that students in Cameroonian institutions dropped out school as a result of challenges linked to electricity and internet connections, which were described as 'demotivating' by the students.

Internet that was provided by the HEI was said to be slow and students tended to use other means to access the internet such as buying a different type of internet bundle. Participants revealed that in this way they were able to access their portal faster and keep up to date with all the notifications from the lecturers. This study also revealed that students using this type of internet connection found it very expensive. A similar study revealed that the high cost of internet was a major challenge and many of the learners found the affordability of internet as a major concern for online learning (Musingafi, Mapuranga, Chiwanza \& Zebron, 2015). 
The findings in this study revealed that while students submit their assignments on time, problems occurred with the time taken to mark those assignments. The study revealed that lecturers often took one to two months to mark assignments and disseminate the assignment marks to students. A similar study conducted by Musingafi, et. al. (2015) revealed that $75 \%$ of their respondents thought that delayed or ineffective feedback was a challenge. Lack of prompt and clear feedback from their lecturers led to students experiencing confusion, anxiety and frustration. Students in the current study further revealed that delayed feedback could be a burden to students who fail to obtain $40 \%$ in the assignments as it means they may miss the re-submission date (second option for students who do not pass an assignment). This may affect students in such a way that they may not qualify to write examinations or they may have to repeat the module the following year. This may result in students having to spend more money and to prolong their studies.

Additionally, students revealed that the lack of face-to-face time with the lecturers affected their studies. Distance and online learning can be impersonal as a result of the lack of face-to-face contacts. This limited the relationship building, which is a requirement for enhanced teaching and learning experiences. The face-to-face, physical, interpersonal contact that inspired the sense of a learning community in a traditional classroom has been reported as being threatened in the online learning mode as technologies does not produce the preferred students' experiences gained from face-to-face interactions (Arasaratnam \& Northcote, 2017; Fincham, 2017). Students also revealed that they were often unable to access lecturers with questions they may have in regard to the modules. This may be as a result of ineffective communication between lecturers and students in the distance mode. Some participants revealed that when they emailed lecturers on issues they did not understand, lecturers could not respond at all or responded in a rude way. This is contrary to a study by Du Plessis et al. (2016), conducted at the University of Namibia, which found that lecturers supported students and were available whenever contacted and would assist students for any encountered problems. Similarly, it was stated that academics should always maintain a vigorous presence on online discussion boards so they control discussion, provide answers and feedback so students remain in the course (Gillett-Swan, 2017). Students studying through the distance mode needed support and guidance from their lecturers to make it through the course. In their study, Islam, Beer, and Slack (2015) concluded that in order for pedagogy to be successful the teacher was required to understand how students learn and then design and deliver course materials and mentor students appropriately so that knowledge and skills are passed on.

Lastly, respondents indicated that they faced discrimination compared to full-time students, stating that they did not receive adequate attention regarding the academic challenges they face. Other discriminatory practices pointed out by participants included that their academic assessments were always last to be marked, thus delaying students from seeing how they have performed. Similarly, Attri (2015) and Fincham (2017) found out that ODL students were discriminated against and felt disconnected from the learning process when it came to receiving feedback from their teachers. This study also revealed that lecturers who facilitated at the ODL at satellite campus of HEI had to teach full-time students, thus giving priority to students studying through the full-time mode. As a result, students often felt that they were not treated fairly compared to full-time students.

The study found that students studying through ODL programme were more likely not to receive adequate study materials or none at all. Furthermore, in some cases, study materials were handed out late. This was one of the major challenges faced by students because the study materials were required to work on assignments and tests. The implications students were likely to perform poorly in assignments and tests. A similar study revealed that a lack of study materials may force students to submit assignments that were not properly written and students likely to write examinations without enough preparation, resulting in poor performance (Musingafi et al., 2015). Another similar study by Du Plessis et al. (2016) found that students on distance mode of study had encountered challenges in terms of receiving their study material on time and this had affected them in terms of submitting their assignments by the due dates. Such poor performance may not be a true reflection of students' academic abilities.

\subsection{Mechanism for Improvement ODL Programmes}

Participants in this study recommended the following measures to address the challenges identified in the study.

Firstly, most participants in this study acknowledged that the appointment of more lecturers at the Centre would improve the turnaround time for feedback on assignments. This would mean that assignments and tests would be marked on time and the students' results would be disseminated timeously, leading to ODL programme being effective and successful. In a similar study, Owusu-Mensah, Anyan, and Denkyi (2015) emphasised the importance of people (staff) to the creation, existence, success and progress of distance education institutions.

It was also evident in this study that students registered for the programme were very dissatisfied with the way study materials were being distributed. Respondents indicated that study materials arrive very late and when they get to the 
centre, the year has almost gone. In a similar study by Musingafi et al. (2015) on the challenges for open and distance learning ODL experienced by students at the Zimbabwe Open University, most of the study respondents had received study materials late or had never received them, affecting students academically, psychologically and financially whereas Gafurov, Safiullin, Akhmetshin, Gapsalamov \& Vasilev (2020) highlighted that convenient access to information regarding available equipment for users bring about improved experience. This study therefore finds it necessary for the HEI to disseminate study materials in a timely manner in order to improve the outcome of the programme and satisfy the students' requirements. By providing study materials on time, students will be able to engage with their respective course from the outset, thus preventing confusion and alleviating the possibility of failure.

It was found in this study that the majority of students who study through ODL were adults with permanent jobs. The ODL centre where the study was carried out in the town situated in an urban area. Students are sometimes based outside this town as they are working at nearby villages. This became a challenge when they had to collect their study materials or simply make enquiries pertaining to their modules because they had to travel long distances to their centres. Participants emphasised that it is expensive to travel every time they had to enquiries or, as often happens, when wrong marks were uploaded on their portals. Participants recommended that HEI should ensure that all small towns and settlements had ODL centres where they could go for assistance when needed. Furthermore, it was found in this study that students studying on distance mode are increasing; this may also cause overcrowding at the HEI during face-to-face interaction with the lecturers and overcrowding during examination time. A similar study by Oroma, Wanga, and Ngumbuke (2015) found that to address this case, measure had to be put in place that forced institutions to open up satellite centres in remote areas.

\section{Conclusions}

It was evident that participants in this study were very dissatisfied with the way study materials were being distributed. Respondents indicated that study materials often arrive very late and when they get to the centre, the year has almost gone. The findings of this study call for well-articulated actions to address the challenges faced by students studying in the distance-learning mode.

\section{Recommendations}

Based on the findings of the study the following recommendations were made:

Lecturers in ODL should ensure the availability and accessibility of prescribed books and recommended books. All prescribed and recommended books should be made available online as far as possible with links given to students. The management at the campus should foster better supervision and coordination regarding the preparation and delivery of study material for students. The HEI should find innovative ways such as Mobile Tele Communication (MTC) internet mobile devices to deal with IT-related challenges to ensure that all distance students have faster access to their portals. In addition, HEI should recruit lecturers who will be solely responsible for ODL students. Lecturers and ODL programme Administrators should undergo refresher training on distance education annually to ensure that they are aware and can address the challenges faced by their students. The HEI should promote the need for face classes in the form of vacation schools at least twice in a semester. HEI should also introduce strict measures to monitor the lecturer's attendance during the face-to-face sessions.

\section{Acknowledgements}

The researchers would like to thank all the respondents who took the time to participate in this study. Without their participation this study would not have been possible. The researchers would also like to thank the HEI for granting permission to conduct the research using its students.

\section{References}

Allen, I. E., Seaman, J., Poulin, R. \& Straut, T. T. (2015). Online report card: Tracking online education in the United States. Online Learning Consortium, 1-62. Retrieved from http://onlinelearningsurvey.com/reports/onlinereportcard.pdf

Arasaratnam, S. L. \& Northcote, M. (2017). Community in online higher education: Challenges and opportunities. The Electronic Journal of e-Learning, 15(2), 188-198. Retrieved from www.ejel.org

Attri, A. K. (2015). Distance education: problems and solutions. International Journal of Behavioral Social and Movement Sciences, 1(4), 42-58.

Brink, H., Van der Walt, C. \& Van Rensburg, G. (2018). Fundamentals of research methodology for health care professionals (4th ed.). Cape Town: Juta. 
Burns, N. \& Grove, S.K. (2015). Understanding nursing research: Building an evidence-based practice. South Africa: Elsevier Health Science.

Cambridge Dictionary Press. (2019). Make your words meaningful. Retrieved 31 July2019 from https://dictionary.cambridge.org

Darling-Hammond, L., Flook, L., Cook-Harvey, C., Barron, B. \& Osher, D. (2019). Implications for educational practice of the science of learning and development. Applied Developmental Science. https://doi.org/10.1080/10888691.2018.1537791

Du Plessis, C. D., Alexander, L., Ashipala, D. O. \& Kamenye, E. (2016). Experiences of student support in the distance mode bachelor of Nursing Science degree at the University of Namibia. International Journal of Higher Education, 5(4). https://doi.org/10.5430/ijhe.v5n4p103

Elawad, H. M. (2017). Writing a scientific research proposal. https://doi.org/10.13140/RG.2.2.14627.04642

Ellis, P. (2018). Understanding research for nursing students (4thed.). United Kingdom: Learning Matters.

Fernando, M. (2018). Pedagogical and e-learning techniques for quality improvement of ICT education. Retrieved from http://dx.org/10.5772/intechopen.72203

Fincham, D. (2017). Implications and Challenges in Studying as a Full Distance Learner on a Masters Programme: Students' Perspectives. International Journal of Higher Education, 6(1), 34-47. https://doi.org/10.5430/ijhe.v6n1p34

Gafurov, IR., Marat Rashitovich Safiullin, MR., Akhmetshin, EM., Gapsalamov, AR. \& Vasilev, VL. (2020). Change of the Higher Education Paradigm in the Context of Digital Transformation: From Resource Management to Access Control. International Journal of Higher Education, 9(3), 71-85. https://doi.org/10.5430/ijhe.v9n3p71

Gillett-Swan, J. (2017). The challenges of online learning supporting and engaging the isolated learner. Journal of Learning Design, 10(1), 20-31. https://doi.org/10.5204/jld.v9i3.293

Government of the Republic of Namibia. (2004). Nursing Act No 8 of 2004. Windhoek, Namibia.

Government of the Republic of Namibia. (2002). Education for all (EFA): National plan of action. Windhoek, Namibia.

Green, J. \& Thorogood, N. (2018). Qualitative methods for health research (4thed.). London:Sage Publications.

Halili, S. H. (2019, January). Technology advancements in education 4.0. The Online Journal of Distance Education and e-Learning, 7(1). Retrieved from www.tojdel.net

Harvey, M. \& Land, L. (2016). Research methods for Nurses and Midwives. London: Sage Publications Ltd

Holloway, I. \& Galvin, K. (2016). Qualitative research in nursing and healthcare (4 ${ }^{\text {th }}$ ed.). United States: Wiley-Blackwell.

IGI Global. (2019). What is higher education institutions (HEIs)? Retrieved July31, 2019, from https://www.igi-global.com/dictionary/information-system-projects-for-highereducation-management/13099

Islam, N., Beer, M. \& Slack, F. (2015). E-learning challenges faced by academics inhighereducation. Journal of Education and Training Studies, 3(5). https://doi.org/10.11114/jets.v3i5.947

James, P.H. \& Murman, J. (2017). Research limitations and the necessity of reporting them. American Journal of Health Education, 35, 66-67. Retrieved from http://libguides.usc.edu/writingguide/limitations

Kanwar, A. S., Cair, A., Ortlieb, K. \& Mohee, R. (2018). Opportunities and challenges for campus-based universities in Africa to translate into dual-mode delivery. Distance Education, 39(2), 140-158.doi:10.1080/01587919.2018.145794

Kentnor, H. E. (2015). Distance education and the evolution of online learning in the United States. Curriculum and Teaching Dialogue, 17(1/2), 21-34.

Layton, S. (2017). What's the difference between online learning and distance learning? Retrieved fromhttps://www.aeseducation.com/blog/2013/09/difference between-online-learning-and-distance-learning

Mahlangu, V. P. (2018). The good, the bad, and the ugly of distance learning in higher education. In M. Sinecen (Ed.), Trends in e-learning. Intech Open. Retrieved from http://dx.doi.org/10.5772/intechopen.75702

Malpads, C. (2018). Everything you need to know about contextual research. Retrieved https://uxdesign.cc/everything-you-need-to-know-about-contextual- 
Maree, K. (2016). First steps in research. Pretoria: Van Schaik.

Mathew, I.R. \& Iloanya, J. E. (2016). Open and distance learning: Benefits and challenges of technology usage for online teaching and learning in Africa. Retrieved July 29, 2019, from https://www.researchgate.net/publication/333817239.

Mellish, M., Brink, L. \& Paton, F. (2016). Teaching and learning the practice of nursing. Johannesburg:Heineman.

Moule, P. \& Aveyard, H. (2016). Nursing research: An introduction (3rded.). London: Sage Publications.

Musingafi, M., Mapuranga, B., Chiwanza, K. \& Zebron, S. (2015). Challenges for open and distance learning (ODL) students: Experiences from students of the Zimbabwe Open University. Journal of Education and Practice, 6(18), 59-66. Retrieved from https://eric.ed.gov/?id=EJ1079750 research-8bb806464d0c

Mahlangu, V. P. (2018). The Good, the Bad, and the Ugly of Distance Learning in Higher Education, Trends in E-learning, Mahmut Sinecen, IntechOpen. https://doi.org/10.5772/intechopen.75702. Available from: https://www.intechopen.com/books/trends-in-e-learning/the-good-the-bad-and-the-ugly-of-distance-learning-inhigher-education

Ndongfack, M. N. (2016). Baseline study on the current state of open and distance learning in Cameroon. Vancouver: Commonwealth of Learning. from http://oasis.col.org/bitstream/handle/11599/2490/2016_Ndongfack_Current-State-ODL

Cameroon.pdf? sequence $=1 \&$ isAllowed $=\mathrm{y}$

Oroma, J. O., Wanga, H. P. \& Ngumbuke, F. (2015). Challenges of e-learning in developing countries: The Ugandan experience. Paper presented at the EDULEARN conference in Barcelona. https://doi.org/10.13140/2.1.4754.1448

Owusu-Mensah, F., Anyan, J. A. \& Denkyi, C. (2015). Staff development practices of open and distance learning institutions in Ghana: The case of the distance education programme of the University of Education, Winneba, Ghana. Journal of Education and Practice, 6(14). Retrieved from https://files.eric.ed.gov/fulltext/EJ1080126.pdf

Palvia, S., Aeron, P., Gupta, P., Mahapatra, D., Ratri, P., Rosner, R. \& Sindhi, S. (2018). Online education: Worldwide status, challenges, trends, and implications. Journal of Global Information Technology Management, 21(4), 233-241. https://doi.org/10.1080/1097198X.2018.1542262

Polit, F.D. \& Beck, C.T. (2017). Nursing research: Generating and assessing evidence for nursing practice (10thed.). China: Lippincott Williams \& Wilkins.

Palvia, S., Aeron, P., Gupta, P., Mahapatra, D., Parida, R., Rosner, R. \& Sindhi, S. (2018). Online Education: Worldwide Status, Challenges, Trends, and Implications. Journal of Global Information Technology Management, 21(4), 233-241, https://doi.org/10.1080/1097198X.2018.1542262

Smyrnova-Trybulska, E., Ogrodzka-Mazur, E., Szafrańska-Gajdzica, A., Morze, N., Makhachashvili, R., Noskova, T. \& Issa, T. (2016). MOOCs - Theoretical and practical aspects: Comparison of selected research results: Poland, Russia, Ukraine, and Australia. In P. Kommers, et al.(Ed.), International Conferences ITS, ICEduTech and STE 2016 (pp. 107-114). Dec 6-8, Melbourne, Australia, ISBN: 978-989-8533-58-6

Taherdoost, H. (2016). Sampling methods in research methodology: How to choose a sampling technique for research. International Journal of Academic Research in Management, 5(2), 18-27. https://doi.org/10.2139/ssrn.3205035

Thesaurus. (2015). The Free Dictionary. Retrieved October 18, 2015, from http://dictionary.reference.com/browse/student.Retrieved 18.10.15

University of Namibia. (1992). University of Namibia Act 18 of 1992. Retrieved fromhttps://www.lac.org.na/laws/annoSTAT/University\%2520of\%2520Namibia

Valdes, R. A., Comendador, V. F. G., Sanz, A. R. \& Castan, J. P. (2018). Aviation 4.0 more safety through automation and Digitization. Aircraft Technology, 2(4), 25-41. http: //dx.doi.org/10.5772/intechopen.73688

Vandeyar, T. (2015). Policy intermediaries and the reform of e-Education in South Africa. British Journal of Educational Technology, 46(2), 344-359. https://doi.org/10.1111/bjet.12130

\section{Note}

P1 refers to participant and number allocated 